\title{
Management and prognostic factors of recurrent pleomorphic adenoma of the parotid gland: personal experience and review of the literature
}

\author{
Luca Oscar Redaelli de Zinis • Michela Piccioni • \\ Antonino Roberto Antonelli • Piero Nicolai
}

Received: 10 August 2007 / Accepted: 10 October 2007 / Published online: 25 October 2007

(C) Springer-Verlag 2007

\begin{abstract}
The aim of this study was to investigate the management and prognostic determinants of recurrent pleomorphic adenoma (RPA). A retrospective analysis was performed to examine the clinical features, the prevalence of surgical complications, and new recurrences of RPA. Tumor recurrence rate was estimated by the Kaplan-Meier method, and the prognostic value of some of the variables was tested by univariate analysis using the log rank test. The study focused on 33 patients, 18 female $(54.5 \%)$ and 15 male (45.5\%), aged 12-71 years (median 41). A total or extended total parotidectomy was performed in 16 cases $(48.5 \%)$, a superficial parotidectomy in 10 cases $(30.3 \%)$, and a local excision in 7 cases $(21.2 \%)$. In ten patients (30.3\%), a branch or the trunk of the facial nerve was deliberately sacrificed. Major complications included one unexpected definitive paralysis of the marginal mandibular branch of the facial nerve and 14 cases of Frey syndrome. Follow-up varied from 2 to 25 years (median 10.5 years), and there were 11 new recurrences $(33.3 \%)$ within a period varying from 1 to 16 years (median 6 years). The estimated tumor recurrence rates were $14.1 \pm 6.6 \%$ at 5 years, $31.4 \pm 9.4 \%$ at 10 years, $43.0 \pm$ $10.8 \%$ at 15 years, and $57.2 \pm 14.8 \%$ at 20 years. Presence of a multinodular lesion and the type of intervention performed were significantly associated with a higher probability of recurrence. RPAs are prone to new recurrences, especially when multinodular and treated with a local excision. Surgical treatment should include facial nerve resection in selected cases. Follow-up for the patient's lifetime is warranted.
\end{abstract}

L. O. Redaelli de Zinis $(\square) \cdot$ M. Piccioni · A. R. Antonelli

P. Nicolai

Department of Otorhinolaryngology,

University of Brescia, Piazza Spedali Civili 1,

25123 Brescia, Italy

e-mail: redaelli@med.unibs.it; lordz@ fastwebnet.it
Keywords Pleomorphic adenoma $\cdot$ Parotid gland neoplasms · Tumor recurrence

\section{Introduction}

Pleomorphic adenoma is the most common neoplasm of the parotid gland. It is a benign tumor composed of epithelial and myoepithelial cells arranged in various morphological patterns. Thinning or absence of the pseudocapsule and the presence of fingerlike projections of the tumor have been observed in all histologic subtypes of pleomorphic adenoma, in particular the myxoid type [1]. Even though many hypotheses for recurrences of parotid gland pleomorphic adenoma have been advanced, including cell biological and genetic factors $[2,3]$, obvious or underestimated tumor spillage, incomplete excision, and violation of the pseudocapsule of the tumor are considered the only proven reasons contributing to recurrent disease [4].

This is why the abandonment of enucleation techniques in favor of more extended surgical procedures, which require the tumor to be excised with the surrounding normal tissue and the facial nerve to be identified and preserved, have dramatically reduced the recurrence rate of pleomorphic adenomas of the parotid gland from $20-45 \%$ to less than $4 \%$ in the last decades [5-7].

However, pure en bloc excision in parotid benign tumor disease has been considered impossible by most surgeons when the pleomorphic adenoma is lying on the facial nerve, and so partial enucleation is often the only surgical option in those cases [5, 7], thus explaining the possibility of recurrence even after proper surgery.

Most of the recent literature on recurrent pleomorphic adenoma (RPA) of the parotid gland has attempted to analyze the causes of primary failure and discusses other possible 
risk factors for recurrence [8-12]; however, there are very few papers focused on the prognostic factors of RPA and retreatment policies [13-18].

The present study was undertaken to address these important issues based on a follow-up period of up to 20 years. Here, we present our findings and review some of the more recent literature.

\section{Materials and methods}

A retrospective analysis of the charts of patients treated for benign parotid neoplasm between 1983 and 2004 was performed to identify those patients operated on for RPA. We collected information on patient demographics and clinical history, clinical features of the lesions, diagnostic work-up, the type of surgery, operative findings, facial nerve management, and adjuvant treatment.

The study analyzed the prevalence of surgical complications and new recurrences. Statistical analysis was performed using the SPSS statistical package. Tumor recurrence rate was estimated by the Kaplan-Meier method: the entry point was the date of surgery for a recurrent tumor seen for the first time in our department, and the end point was the date of a new recurrence or the date of last consultation for censored observations.

The prognostic value of certain categorical variables (age, gender, number of previous operations, type of previous operation, lobe of origin, type of surgery performed for RPA, maximum diameter, facial nerve resection, presence of a pseudocapsule at the surgical margins, rupture of the pseudocapsule, number of neoplastic nodules, postoperative radiotherapy) was tested by univariate analysis using the log rank test.

\section{Results}

Among 524 patients treated for a benign parotid neoplasm between 1983 and 2004, 33 underwent surgical treatment for RPA. Eighteen (54.5\%) patients were female and $15(45.5 \%)$ male; their ages ranged from 12 to 71 years (median 41 ). None had been previously affected by a malignant neoplasm or submitted to radiation treatment. Seven patients were previously operated on in our department (with a prevalence of recurrence after first treatment of $1.3 \%$ ) and 26 patients had previous surgical treatment(s) performed elsewhere. A summary of the patient's previous clinical history is reported in Table 1. A swelling in the parotid region was the most significant complaint for $87.9 \%$ (29/33) of patients when they came to our attention for the recurrence; pain or facial nerve paresis was associated with the swelling in two cases. In four $(12.1 \%)$ cases, the relapse was recognized by routine postop-
Table 1 Summary of clinical history of patients treated for the first time at the Department of Otolaryngology of the University of Brescia for RPA of the parotid gland

\begin{tabular}{ll}
\hline Previous recurrences & \\
One & $63.6 \%(21)$ \\
Two & $18.2 \%(6)$ \\
Three & $12.1 \%(4)$ \\
Four & $6.1 \%(2)$ \\
Median time to recurrence & \\
First recurrence (33) & 6 years (range 1-23) \\
Second recurrence (12) & 5 years (range 2-28) \\
Third recurrence (6) & 5.5 years (range 3-19) \\
Fourth recurrence (2) & 8 years (both patients) \\
Last operation & \\
Subtotal parotidectomy & $33.3 \%(11)$ \\
Local excision & $33.3 \%(11)$ \\
Superficial parotidectomy & $21.2 \%(7)$ \\
Not reported & $12.1 \%(4)$ \\
\hline
\end{tabular}

Number of patients in parentheses

erative follow-up examinations. Other complaints, present from previous surgeries, were facial nerve paralysis in four patients and Frey syndrome in one.

Ultrasonography was the most frequently used diagnostic tool (23 patients, 69.7\%), followed by fine needle aspiration biopsy in $21(63.6 \%)$ patients, magnetic resonance imaging in 14 (42.4\%), computed tomography in 3 (9.1\%), and sialography in $2(6.1 \%)$. The different types of diagnostic procedures employed reflect the multi-decade period analyzed. At present, after ultrasonography, which is routinely adopted for follow-up, magnetic resonance imaging is used to delineate the extension of the recurrent lesions.

In $12(36.4 \%)$ patients, the lesion involved the superficial lobe of the parotid gland, in $9(27.3 \%)$ both lobes, and in $12(36.4 \%)$ only the deep lobe was involved. In 5 (15.2\%) patients the lesion also extended to the parapharyngeal space. Information on multinodularity of the lesion could be obtained for 31 patients: multiple lesions were observed in $24(77.4 \%)$ of them.

Surgical treatment was tailored to the single patient in an attempt to obtain a margin of healthy tissue (Table 2). Postoperative complications are listed in Table 3. Nine (27.3\%) patients were submitted to postoperative radiotherapy. There were no standard criteria for postoperative radiotherapy, but it was performed when the excision did not guarantee sufficient free margins of healthy tissue based on the judgment of the surgeon.

The patients were followed by yearly ultrasonography. Follow-up varied from 2 to 25 years (median 10.5 years). Three patients died from a metachronous malignant neoplasm, one of them after a new recurrence. The other 
Table 2 Surgical treatment for RPA of the parotid gland at the Department of Otolaryngology of the University of Brescia

\begin{tabular}{ll}
\hline Total or extended total parotidectomy & $48.5 \%(16)$ \\
Superficial parotidectomy & $30.3 \%(10)$ \\
Local excision & $21.2 \%(7)$ \\
Partial or total facial nerve resection & $30.3 \%(10)$ \\
\hline
\end{tabular}

Number of patients in parentheses

Table 3 Postoperative complications of patients treated for RPA of the parotid gland at the Department of Otolaryngology of the University of Brescia

\begin{tabular}{ll}
\hline Frey syndrome & $43.7 \%(14 / 32)$ \\
$\begin{array}{l}\text { Temporary paresis of a branch } \\
\text { or of the entire facial nerve }\end{array}$ & $30.4 \%(7 / 23)$ \\
$\begin{array}{l}\text { Definitive paralysis of the marginal } \\
\quad \text { mandibular branch of the facial nerve }\end{array}$ & $4.3 \%(1 / 23)$ \\
Salivary fistula & $3.0 \%(1 / 33)$ \\
Keloid & $3.0 \%(1 / 33)$ \\
\hline
\end{tabular}

patients are still alive. Overall, $11(33.3 \%)$ new recurrences were observed. No patient with a single node had a recurrence. Four of the new recurrences had been operated on again and one had a further recurrence. Seven patients with small (less than $1 \mathrm{~cm}$ ) and stable new recurrences are still on follow-up. The time for new recurrence varied from 1 to 16 years (median 6 years). There were 2 cases of focal atypical cells but no malignant transformation in the new recurrences. Distribution of the recurrences in relation to the different variables under analysis is shown in Table 4. The estimated tumor recurrence rates were $14.1 \pm 6.6 \%$ at 5 years, $31.4 \pm 9.4 \%$ at 10 years, $43.0 \pm 10.8 \%$ at 15 years, and $57.2 \pm 14.8 \%$ at 20 years (Fig. 1). Among the variables evaluated with the log-rank test, only the presence of a multinodular recurrence and the type of intervention performed were significantly associated with a higher probability of a new recurrence (Table 5). The high variation in tumor recurrence rates observed after 20 years of follow-up (Table 5) is probably related to the low number of patients with longer follow-up times.

\section{Discussion}

It is generally accepted that the standard treatment of pleomorphic adenoma of the parotid gland is a formal parotidectomy or at least the removal of the tumor with a surrounding cuff of normal parotid tissue after identification, dissection and preservation of the facial nerve [7]. Unfortunately, if the tumor is in contact with the facial nerve, even a total parotidectomy can not guarantee the presence of a cuff of normal tissue, because the surgeon
Table 4 Distribution of the new recurrences after treatment for RPA of the parotid gland at the Department of Otolaryngology of the University of Brescia (No. $=11 ; 33.3 \%)$

\begin{tabular}{|c|c|c|c|}
\hline \multicolumn{2}{|l|}{ Variable } & \multirow{2}{*}{$\frac{\%}{30.0}$} & \multirow{2}{*}{$\frac{P \text {-value }}{1}$} \\
\hline Age & $\leq 30$ years $(3 / 10)$ & & \\
\hline & $>30$ years $(8 / 23)$ & 34.8 & \\
\hline \multirow[t]{2}{*}{ Gender } & Female (4/18) & 22.2 & 0.1 \\
\hline & Male (7/15) & 46.7 & \\
\hline \multirow{2}{*}{$\begin{array}{l}\text { Number of previous } \\
\text { operations }\end{array}$} & $1(7 / 21)$ & 33.3 & 1 \\
\hline & $>1(4 / 12)$ & 33.3 & \\
\hline \multirow{2}{*}{$\begin{array}{l}\text { Type of previous } \\
\text { operations }\end{array}$} & Enucleation $(2 / 11)$ & 18.2 & 0.2 \\
\hline & Parotidectomy (8/18) & 44.4 & \\
\hline \multirow[t]{2}{*}{ Lobe of origin } & Superficial $(5 / 21)$ & 23.8 & 0.1 \\
\hline & Deep (6/12) & 50.0 & \\
\hline \multirow[t]{2}{*}{ Intervention performed } & Parotidectomy (6/26) & 23.1 & 0.02 \\
\hline & Other $(5 / 7)$ & 71.4 & \\
\hline \multirow[t]{2}{*}{ Maximum diameter } & $\leq 2 \mathrm{~cm}(7 / 16)$ & 43.8 & 0.3 \\
\hline & $>2 \mathrm{~cm}(3 / 15)$ & 20.0 & \\
\hline \multirow[t]{2}{*}{ Facial nerve resection } & No $(7 / 23)$ & 30.4 & 0.7 \\
\hline & Yes $(4 / 10)$ & 40.0 & \\
\hline \multirow{2}{*}{$\begin{array}{l}\text { Involvement of } \\
\text { surgical margins }\end{array}$} & No $(8 / 23)$ & 34.8 & 0.5 \\
\hline & Yes $(2 / 8)$ & 25.0 & \\
\hline \multirow[t]{2}{*}{ Capsular rupture } & No $(6 / 23)$ & 26.1 & 0.2 \\
\hline & Yes $(4 / 8)$ & 50.0 & \\
\hline \multirow[t]{2}{*}{ Multiple nodules } & No $(0 / 7)$ & 0 & 0.04 \\
\hline & Yes (10/24) & 41.7 & \\
\hline \multirow{2}{*}{$\begin{array}{l}\text { Postoperative } \\
\text { radiotherapy }\end{array}$} & No $(9 / 24)$ & 37.5 & 0.3 \\
\hline & Yes $(2 / 9)$ & 22.2 & \\
\hline
\end{tabular}

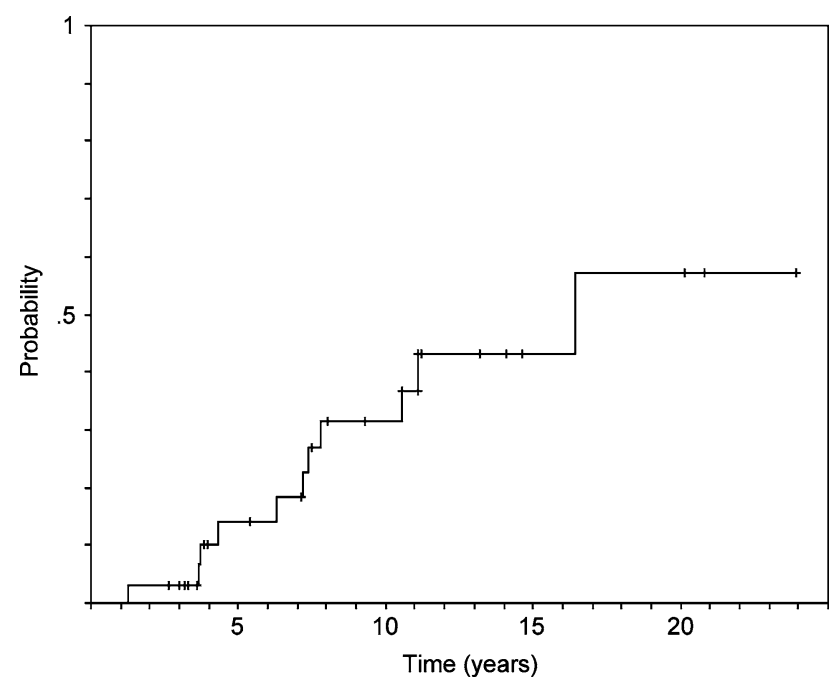

Fig. 1 Estimated recurrence rate after treatment for recurrent pleomorphic adenoma of the parotid gland at the Department of Otolaryngology of the University of Brescia (Kaplan-Meier method)

must carry on the dissection between the tumor and the branches of the nerve with the risk of leaving microscopic disease behind or causing microscopic spillage of the 
Table 5 Estimated tumor recurrence rates after treatment for RPA of the parotid gland at the Department of Otolaryngology of the University of Brescia (log-rank test)

\begin{tabular}{|c|c|c|c|c|c|c|}
\hline \multirow[t]{2}{*}{ Variable } & & \multicolumn{4}{|c|}{ Estimated tumor recurrence rates $(\%)$} & \multirow[t]{2}{*}{$P$-value } \\
\hline & & 5-year & 10-year & 15-year & 20-year & \\
\hline \multirow[t]{2}{*}{ Age } & $\leq 30$ years $(10)$ & $12.5 \pm 11.7$ & $41.7 \pm 18.6$ & - & - & \multirow[t]{2}{*}{0.8} \\
\hline & $>30$ years $(23)$ & $14.7 \pm 7.9$ & $26.9 \pm 10.5$ & $42.4 \pm 12.8$ & $56.8 \pm 15.7$ & \\
\hline \multirow[t]{2}{*}{ Gender } & Female (18) & $13.4 \pm 9.0$ & $30.7 \pm 13.1$ & $30.7 \pm 13.1$ & $30.7 \pm 13.1$ & \multirow[t]{2}{*}{0.4} \\
\hline & Male (15) & $14.3 \pm 9.4$ & $30.7 \pm 13.0$ & $56.7 \pm 15.1$ & $71.1 \pm 16.3$ & \\
\hline \multirow[t]{2}{*}{ Number of previous operations } & $1(21)$ & $11.8 \pm 7.9$ & $25.4 \pm 11.1$ & $45.6 \pm 14.7$ & $63.7 \pm 17.8$ & \multirow[t]{2}{*}{0.9} \\
\hline & $>1(12)$ & $18.5 \pm 11.9$ & $41.8 \pm 16.3$ & $41.8 \pm 16.3$ & $41.8 \pm 16.3$ & \\
\hline \multirow[t]{2}{*}{ Type of last previous operation } & Enucleation (11) & $9.1 \pm 8.7$ & $24.2 \pm 15.6$ & $24.2 \pm 15.6$ & $24.2 \pm 15.6$ & \multirow[t]{2}{*}{0.2} \\
\hline & Parotidectomy (18) & $20.0 \pm 10.3$ & $45.1 \pm 14.0$ & $58.9 \pm 15.9$ & 100 & \\
\hline \multirow[t]{2}{*}{ Lobe of origin } & Superficial (21) & 0 & $13.8 \pm 9.1$ & $32.1 \pm 13.6$ & $54.8 \pm 20.6$ & \multirow[t]{2}{*}{0.07} \\
\hline & Deep (12) & $35.8 \pm 14.4$ & $59.9 \pm 16.4$ & $59.9 \pm 16.4$ & $59.9 \pm 16.4$ & \\
\hline \multirow[t]{2}{*}{ Intervention performed } & Parotidectomy (26) & $5.3 \pm 5.1$ & $16.4 \pm 8.7$ & $30.5 \pm 11.7$ & $47.9 \pm 17.4$ & \multirow[t]{2}{*}{0.001} \\
\hline & Other (7) & $42.9 \pm 18.7$ & - & - & - & \\
\hline \multirow[t]{2}{*}{ Maximum diameter } & $\leq 2 \mathrm{~cm}(16)$ & $19.6 \pm 10.2$ & $26.9 \pm 11.6$ & $44.3 \pm 14.0$ & $72.2 \pm 20.9$ & \multirow[t]{2}{*}{0.4} \\
\hline & $>2 \mathrm{~cm}(15)$ & $10.0 \pm 9.5$ & $32.5 \pm 15.5$ & $32.5 \pm 15.5$ & $32.5 \pm 15.5$ & \\
\hline \multirow[t]{2}{*}{ Facial nerve resection } & No (23) & $9.4 \pm 6.3$ & $27.2 \pm 10.6$ & $35.3 \pm 12.1$ & $51.4 \pm 16.7$ & \multirow[t]{2}{*}{0.4} \\
\hline & Yes (10) & $25.0 \pm 15.3$ & $40.0 \pm 18.2$ & - & - & \\
\hline \multirow[t]{2}{*}{ Involvement of surgical margins } & No (23) & $14.0 \pm 7.5$ & $24.7 \pm 9.7$ & $37.9 \pm 11.7$ & $53.4 \pm 16.0$ & \multirow[t]{2}{*}{0.3} \\
\hline & Yes (8) & $25.0 \pm 21.7$ & $62.5 \pm 28.6$ & - & - & \\
\hline \multirow[t]{2}{*}{ Capsular rupture } & No (23) & $16.4 \pm 8.8$ & $38.7 \pm 12.8$ & $38.7 \pm 12.8$ & $38.7 \pm 12.8$ & \multirow[t]{2}{*}{0.8} \\
\hline & Yes (8) & $12.5 \pm 11.7$ & $12.5 \pm 11.7$ & $40.0 \pm 18.2$ & 100 & \\
\hline \multirow[t]{2}{*}{ Multiple nodules } & No (7) & 0 & 0 & 0 & 0 & \multirow[t]{2}{*}{0.02} \\
\hline & Yes (24) & $19.6 \pm 8.9$ & $36.8 \pm 11.2$ & $53.2 \pm 13.4$ & 100 & \\
\hline \multirow[t]{2}{*}{ Postoperative radiotherapy } & No (24) & $14.2 \pm 7.7$ & $34.3 \pm 11.8$ & $48.9 \pm 12.9$ & $65.9 \pm 16.4$ & \multirow[t]{2}{*}{0.3} \\
\hline & Yes (9) & $12.5 \pm 11.6$ & $25.0 \pm 15.3$ & $25.0 \pm 15.3$ & $25.0 \pm 15.3$ & \\
\hline
\end{tabular}

tumor. This accounts for $1-4 \%$ probability of recurrence [5, 7]. These low percentages, together with the increasing number of institutions that treat parotid neoplasms, have reduced the number of cases of RPA being referred to a single institution; this, in turn, has contributed to a lack of experience in managing these tumors. Moreover, with the number of reported patients usually varying from less than 15 to about 50 [6, 8, 9, 11, 12, 14-17, 19-24], and only a few studies reporting about a hundred patients [10, 13, 18, $25]$, there has been relatively little discussion of the prognostic factors for RPA [13-18].

Follow-up of parotidectomies is currently performed by ultrasonography, but most patients do not avail themselves of regular follow-up and only $12.1 \%$ of our patients with an RPA were diagnosed by routine ultrasonography, while the majority came to our observation for a swelling in the parotid region. In $77.4 \%$ of our patients, there was a multinodular lesion (in Stennert et al. [4], 90\% were multinodular at pathologic examination), reinforcing the pathogenetic hypothesis of incomplete excision, violation of the pseudocapsule of the tumor, or obvious or underestimated tumor spillage during the first surgery due to the impossibility of obtaining healthy free margins when the lesion is adjacent to the facial nerve.

Delineation of the extension of the RPA is better depicted by MRI, which better demonstrates the multinodular nature of the disease [24] and potential deep-lobe or parapharyngeal extension. Many patients that we treated came from other institutions without clear documentation of their previous treatment(s); in such cases, MRI can also help in determining the amount of parotid gland still present after any previous surgery. The signal and enhancement characteristics of RPA of the parotid gland are nonspecific [26]. The lesions are usually round; they are of low intensity on T1-weighted images and of high intensity on T2weighted MR images. With contrast administration, the lesions show mild enhancement [26]. However, MRI can also be inadequate for identifying all nodules, and frequently the surgeon's microscope or the pathologist's microscope reveals many more nodules than suspected from clinical assessment [4].

Management options for RPA include observation only, localized resection, resection with facial nerve dissection, 
wide-field resection with facial nerve sacrifice, and radiotherapy [2, 4, 24]. Only observation has been suggested for the elderly or medically infirm patient $[2,4,24]$. When surgical excision is considered, it should be tailored to the individual patient $[19,23]$. In general, it is recommended to resect the scars of any previous surgery. Localized resection of the tumor has been employed after multiple recurrences or after previous total parotidectomy when it is the only option to preserve the facial nerve [10,14]. Superficial or total parotidectomy, depending on the location of the recurrence, has been suggested when the previous operation was a simple local excision [6, 8-15, 17, 18, 20, 23-25]. Radical and extended parotidectomies have been considered for patients with infiltration of branches or the main trunk of the facial nerve, and in cases of multinodular recurrences [9, 11-13, 15, 18, 23-25]. In particular, facial nerve resection has been suggested for patients with a history of multiple recurrences or failed radiotherapy [24]. In $30.3 \%$ of our patients, the resection of at least a branch of the facial nerve was performed (Table 2). Facial nerve dissection and preservation were performed in all cases with still healthy parotid tissue between the nerve and the tumor, and in the case of facial nerve encasement when a patient refused facial nerve resection. The observation of many cases with unexpected multinodularity persuaded Stennert et al. [4] to routinely perform a total parotidectomy for all RPAs. However, such an aggressive policy of treatment does not prevent leaving microscopic residuals; indeed, a recent study by the same group reported a $52 \%$ probability of new recurrences [18].

The role of radiotherapy remains questionable $[9,13,16$, $17,24,27]$. Some authors suggest that radiotherapy should be reserved only for malignant tumors since it carries, especially in young people, a risk of malignant transformation that increases over time [17]. Nonetheless, its use is not infrequent [6, 9, 13-16, 19, 20, 27]. Jackson et al. [9] used postoperative radiotherapy in patients in whom histology showed that resection margins of the specimen were not free of tumor or in those with intraoperative spillage of tumor. Renehan et al. [13] recommended postoperative radiotherapy in multinodular recurrences. Douglas et al. [16] reported their experience of fast neutron radiotherapy and recommended radiotherapy for selected cases: when complete extirpation is not possible, when sacrifice of the facial nerve is necessary, or after multiple recurrences. Glas et al. [17] suggested postoperative radiotherapy for difficult cases in which further surgical treatment of recurrent disease is not recommended for technical reasons. Kamida et al. [27] suggested the use of stereotactic radiosurgery for difficult selected cases, such as the patient they treated for skull base invasion with no regrowth after 5 years. Our experience, including only nine patients, is too limited to draw any conclusion about indications for radiation therapy.
Complications of treatment of RPA are similar to those for primary surgery for parotid pleomorphic adenoma. The main difference is the higher risk of facial nerve damage in the former, with unexpected permanent facial nerve paralysis in more than $30 \%$ of cases [24].

Even though we did not have cases of malignant transformation, a high incidence is expected, especially after multiple recurrences, reaching up to $15 \%$ in the experience of Mercante et al. [22].

The main purpose of our study was to analyze risk factors for new recurrence after treatment for RPA. The percentage of new recurrences varies from 10 to $58 \%[8,10,12-15,17-$ $20,23-25]$. In two surveys of the literature with a 10 -year follow-up, the prevalence of a new recurrence was 43 and $45 \%$, respectively [12, 25]. Wittekindt et al. [18] reported a recurrence rate increasing from $42 \%$ at 5 years to $75 \%$ at 15 years. We observed a prevalence of $33.3 \%$ with an estimation of recurrence rate increasing from $14.1 \pm 6.6 \%$ at 5 years to $31.4 \pm 9.4 \%$ at 10 years, $43.0 \pm 10.8 \%$ at 15 years, and $57.2 \pm 14.8 \%$ at 20 years (Fig. 1).

Among the variables tested with the log-rank test against the estimated new recurrence rate (Table 5), just two were significantly associated with the likelihood of developing a new recurrence: local excision of the RPA instead of a formal parotidectomy and the presence of multinodular disease. To date, no new recurrences have been observed for uninodular recurrences. There was a trend toward increased risk of a new recurrence for deep-lobe localization, although it was not statistically significant.

Few papers have analyzed prognostic factors for RPA [13-18]. Renehan et al. [13] studied 114 patients with firstrecurrence RPA and reported significantly better, new recurrence-free survival for patients treated with postoperative radiotherapy when the RPA was multinodular. Age, gender, time to first recurrence, and the type of prior treatment were all not significant predisposing factors for a new recurrence [13]. Yugueros et al. [14] followed 39 patients treated for RPA at their institution: they found no significant difference in development of another recurrence in relation to gender, time after the previous treatment, size of the tumor, type of resection, and postoperative radiotherapy. Carew et al. [15] analyzed 31 patients treated for RPA and concluded that the extent of the first parotid operation was the only factor with a statistically significant impact on tumor control after resection of the recurrence. Local control was achieved in all patients whose initial procedures involved local excision. Superficial lobe location and postoperative radiotherapy showed better results but were not significant [15]. Fast neutron radiotherapy of 16 patients with residuals of RPA stopped progression of the tumor in patients without gross residuals, without multifocal disease and with an interval from diagnosis of less than 25 years; however, the results were not statistically significant [16]. Glas et al. [17] ana- 
lyzed 52 patients with RPA, treated after one or more recurrences: no significant influence was seen in the recurrence rate with respect to gender, age at initial treatment, time of first recurrence, and intraoperative tumor spillage. Wittekindt et al. [18], in a group of 108 patients, observed a significantly higher rate of new recurrences in female patients, in younger patients, and in patients treated with a simple enucleation.

\section{Conclusion}

The management of RPA is a major challenge for the clinician. RPAs, particularly multinodular tumors, are prone to new recurrences especially when treatment of the initial tumor is performed according to currently accepted standards. MRI is considered to be the best tool to delineate the extension of the lesion, although it can miss microscopic nodules. Options for management include pure observation, not only for the elderly or infirm, but also in cases of small lesions until they begin to grow. When surgery is elected, it should be tailored to the single patient, because even if on one side a limited local excision is considered acceptable, on the other side a total or extended parotidectomy may be inadequate to control an RPA adjacent to the nerve. In these cases, facial nerve resection and reconstruction must also be considered and discussed with the patient in the preoperative counseling. Postoperative radiotherapy is an option, particularly for older patients for whom the risk of inducing other malignancies is considered to be low. Follow-up for patients treated for RPA should be done with regular ultrasonography for the lifetime of the patient and with magnetic resonance in selected cases with deep lobe or parapharyngeal involvement. All patients should be informed about the possibility of the need for multiple treatment procedures.

\section{References}

1. Stennert E, Guntinas-Lichius O, Klussmann JP, Arnold G (2001) Histopathology of pleomorphic adenoma in the parotid gland: a prospective unselected series of 100 cases. Laryngoscope 111:2195-2200

2. Bradley PJ (2001) Recurrent salivary gland pleomorphic adenoma: etiology, management, and results. Curr Opin Otolaryngol Head Neck Surg 9:100-108

3. Hamada T, Matsukita S, Goto M, Kitajima S, Batra SK, Irimura T, Sueyoshi K, Sugihara K, Yonezawa S (2004) Mucin expression in pleomorphic adenoma of salivary gland: a potential role for MUC1 as a marker to predict recurrence. J Clin Pathol 57:813-821

4. Stennert E, Wittekindt C, Klussmann JP, Arnold G, GuntinasLichius O (2004) Recurrent pleomorphic adenoma of the parotid gland: a prospective histopathological and immunohistochemical study. Laryngoscope 114:158-163

5. Donovan DT, Conley JJ (1984) Capsular significance in parotid tumor surgery: reality and myths of lateral lobectomy. Laryngoscope 94:324-329
6. Leverstein H, Tiwari RM, Snow GB, van der Wal JE, van der Waal I (1997) The surgical management of recurrent or residual pleomorphic adenomas of the parotid gland. Analysis and results in 40 patients. Eur Arch Otorhinolaryngol 254:313-317

7. Witt RL (2002) The significance of the margin in parotid surgery for pleomorphic adenoma. Laryngoscope 112:2141-2154

8. Myssiorek D, Ruah CB, Hybels RL (1990) Recurrent pleomorphic adenomas of the parotid gland. Head Neck 12:332-336

9. Jackson SR, Roland NJ, Clarke RW, Jones AS (1993) Recurrent pleomorphic adenoma. J Laryngol Otol 107:546-549

10. Laskawi R, Schott T, Schroder M (1998) Recurrent pleomorphic adenomas of the parotid gland: clinical evaluation and long-term follow-up. Br J Oral Maxillofac Surg 36:48-51

11. Patel N, Poole A (1998) Recurrent benign parotid tumours: the lesson not learnt yet? Aust N Z J Surg 68:562-564

12. Zbaren P, Tschumi I, Nuyens M, Stauffer E (2005) Recurrent pleomorphic adenoma of the parotid gland. Am J Surg 189:203207

13. Renehan A, Gleave EN, McGurk M (1996) An analysis of the treatment of 114 patients with recurrent pleomorphic adenomas of the parotid gland. Am J Surg 172:710-714

14. Yugueros P, Goellner JR, Petty PM, Woods JE (1998) Treating recurrence of parotid benign pleomorphic adenomas. Ann Plast Surg 40:573-576

15. Carew JF, Spiro RH, Singh B, Shah JP (1999) Treatment of recurrent pleomorphic adenomas of the parotid gland. Otolaryngol Head Neck Surg 121:539-542

16. Douglas JG, Einck J, Austin-Seymour M, Koh WJ, Laramore GE (2001) Neutron radiotherapy for recurrent pleomorphic adenomas of major salivary glands. Head Neck 23:1037-1042

17. Glas AS, Vermey A, Hollema H, Robinson PH, Roodenburg JL, Nap RE, Plukker JT (2001) Surgical treatment of recurrent pleomorphic adenoma of the parotid gland: a clinical analysis of $52 \mathrm{pa}-$ tients. Head Neck 23:311-316

18. Wittekindt C, Streubel K, Arnold G, Stennert E, Guntinas-Lichius O (2007) Recurrent pleomorphic adenoma of the parotid gland: analysis of 108 consecutive patients. Head Neck 29:822-828

19. Samson MJ, Metson R, Wang CC, Montgomery WW (1991) Preservation of the facial nerve in the management of recurrent pleomorphic adenoma. Laryngoscope 101:1060-1062

20. Rowley H, Murphy M, Smyth D, O’Dwyer TP (2000) Recurrent pleomorphic adenoma: uninodular versus multinodular disease. Ir J Med Sci 169:201-203

21. Becelli R, Perugini M, Mastellone P, Frati R (2001) Surgical treatment of recurrences of pleomorphic adenoma of the parotid gland. J Exp Clin Cancer Res 20:487-489

22. Mercante G, Makeieff M, Guerrier B (2002) Ruolo della chirurgia nelle recidive dei tumori benigni della parotide. Acta Otorhinolaryngol Ital 22:80-85

23. Maxwell EL, Hall FT, Freeman JL (2004) Recurrent pleomorphic adenoma of the parotid gland. J Otolaryngol 33:181-184

24. Leonetti JP, Marzo SJ, Petruzzelli GJ, Herr B (2005) Recurrent pleomorphic adenoma of the parotid gland. Otolaryngol Head Neck Surg 133:319-22

25. Phillips PP, Olsen KD (1995) Recurrent pleomorphic adenoma of the parotid gland: report of 126 cases and a review of the literature. Ann Otol Rhinol Laryngol 104:100-104

26. Koral K, Sayre J, Bhuta S, Abemayor E, Lufkin R (2003) Recurrent pleomorphic adenoma of the parotid gland in pediatric and adult patients: value of multiple lesions as a diagnostic indicator. AJR Am J Roentgenol 180:1171-1174

27. Kamida T, Abe T, Inoue R, Kobayashi H, Suzuki M, Matsumoto A (2005) Stereotactic radiosurgery for recurrent pleomorphic adenoma invading the skull base: case report. Neurol Med Chir (Tokyo) 45:161-163 